\title{
Implementing a cross-course design for online international exchange in geography courses
}

\author{
Leonieke Bolderman ${ }^{1}$, Peter Groote ${ }^{2}$, Euan Hague ${ }^{3}$, \\ Jellina Timmer ${ }^{4}$, Hanneke Boode ${ }^{5}$, and Sake Jager ${ }^{6}$
}

Abstract

T n 2017, the University of Groningen (UG) in The Netherlands and DePaul University in the USA (DePaul) connected undergraduate students in geography courses using an Online International Exchange (OIE) assignment involving videoconferencing. Whereas many international OIE projects are designed on joint alignment principles connecting similar courses and developing similar aims and assignments, this project had a cross-course setup with diverging learning outcomes. In the UG course, OIE was a pretravel activity primarily aimed at developing disciplinary skills. DePaul implemented OIE as an intercultural awareness assignment. Through reflection on the design process and thematic analysis of student reflections, we conclude that the OIE introduced students in the DePaul course to international perceptions and encouraged self-reflection, while the OIE stimulated disciplinary skills and introduced intercultural awareness to the UG course. Moreover, OIE stimulated cross-cultural project management skills, increasing awareness of differing educational and urban contexts and thereby training the students in global citizenship. Therefore, this cross-course OIE shows that adapting OIE design to

\footnotetext{
1. University of Groningen, Faculty of Spatial Sciences, The Netherlands; s.l.bolderman@rug.nl; https://orcid.org/0000-0003-4411-9292

2. University of Groningen, Faculty of Spatial Sciences, The Netherlands, p.d.groote@rug.nl; https://orcid.org/0000-0002-9642-4013

3. DePaul University, School of Public Service, Chicago, United States of America; ehague@depaul.edu; https://orcid.org/0000-0002-5776-2562

4. University of Groningen, Educational Support and Innovation Department, The Netherlands, j.m.timmer@rug.nl

5. University of Groningen, Faculty of Science and Engineering, The Netherlands, j.m.c.boode@rug.nl

6. University of Groningen, the Netherlands; s.jager@rug.nl, UNIcollaborate 182; https://orcid.org/0000-0002-0929-2084
}

How to cite this article: Bolderman, L., Groote, P., Hague, E., Timmer, J., Boode, H., \& Jager, S. (2020). Implementing a cross-course design for online international exchange in geography courses. Journal of Virtual Exchange, 3, 59-72. https://doi.org/10.21827/jve.3.35838 
local curricular needs using pre-existing courses can enhance and deepen disciplinary specific learning outcomes through cross fertilization, and may create unexpected new learning outcomes. This expands the potential application and benefits of OIE for the internationalization of higher education.

Keywords: human/urban geography; pre-mobility preparation; online international exchange; experiential learning; intercultural awareness.

\section{Introduction}

In 2017, UG and DePaul implemented an OIE, based on a cross-course model that connected students from two separate undergraduate geography courses through videoconferencing. The main innovative aspects of this OIE activity were: (1) different learning outcomes and different roles for the UG and DePaul students in the same OIE project; and (2) a focus on disciplinary content and skills instead of language acquisition.

Drawing from each program's different learning outcomes, the OIE assignment introduced students in the DePaul course to international perceptions and encouraged self-reflection, while the UG course assignment stimulated disciplinary skills and introduced intercultural awareness. Moreover, the specific OIE assignment unexpectedly stimulated the cross-cultural project management skills of the students, showing how OIE can contribute to developing 'global citizens' (De Wit, 2016). This innovative cross-course design shows how OIE can be implemented flexibly within existing courses, supporting the development of discipline-specific skills. This potentially expands the application and benefits of OIE for the internationalization of higher education.

\section{Context}

The undergraduate Human Geography program at UG has long incorporated a course called Fieldwork Abroad. Since 2015, when the fieldwork started to take place in Chicago, faculty in DePaul's geography department collaborated with UG faculty, both as experts giving lectures on local development and urban planning, and as co-authors (e.g. Hague \& Groote, 2016). Building on these prior personal relationships, when preparing the 2017 UG Fieldwork Abroad course, the existing cooperation was intensified through an OIE that was developed by the authors of this practice report: the three teachers involved, and three educational experts. 
The educational experts were involved since at both universities the OIE project contributed to larger initiatives. UG has promoted OIE since 2017 as a cross-disciplinary educational practice (University of Groningen, n.d.), and a key point of departure for UG in the Fieldwork Abroad course described here was to identify how learning disciplinary skills can be enhanced by engaging students online in collaborative tasks with peers from universities in other countries. At DePaul, the OIE was embedded in its University-wide Global Learning Experience (GLE) program that had been initiated in 2015, aiming to offer international experiences to as many students as possible (DePaul University, n.d.a). This OIE fitted both the UG interest in online, international learning of disciplinary skills, as well as DePaul's key objective of offering international engagement. These diverging aims were translated into separate, local learning outcomes for the OIE assignment (see Table 1). Further, both courses existed prior to OIE implementation, each with separate course and program learning outcomes, to which the OIE learning outcomes needed to connect.

\section{Table 1. Overview of learning outcomes}

\begin{tabular}{|c|c|c|}
\hline \multicolumn{3}{|l|}{ Learning Outcomes } \\
\hline & DePaul & UG \\
\hline \multirow[t]{2}{*}{$\begin{array}{l}\text { Program level (DePaul) } \\
\text { / Course level (UG) }\end{array}$} & $\begin{array}{l}\text { Students are able to interpret spatial } \\
\text { patterns of economic inequalities and } \\
\text { social injustices and their relation to } \\
\text { urban, built, and natural environments. }\end{array}$ & $\begin{array}{l}\text { Students are able to apply the knowledge, } \\
\text { research skills and communicative skills } \\
\text { obtained in the undergraduate program, in } \\
\text { a (spatial) context that is unfamiliar to them. }\end{array}$ \\
\hline & $\begin{array}{l}\text { Students gain “an understanding of key } \\
\text { concepts, theories, and vocabulary to } \\
\text { interpret how socio-cultural, political, } \\
\text { economic, and/or environmental } \\
\text { phenomena may construct a 'space', a } \\
\text { 'place', a 'landscape', a 'location', or a } \\
\text { 'region' as a complex material or symbolic } \\
\text { structure” (DePaul University, n.d.b, p. 458). }\end{array}$ & $\begin{array}{l}\text { Through experiential learning, students } \\
\text { learn about socio-spatial developments } \\
\text { while on (international) location. }\end{array}$ \\
\hline \multirow[t]{2}{*}{ OIE component } & $\begin{array}{l}\text { Intercultural awareness: by exchanging } \\
\text { ideas, students are able to reflect on } \\
\text { their own and their fellow students' } \\
\text { implicit ideas, and how these may } \\
\text { differ between peers with different } \\
\text { cultural (national) backgrounds. }\end{array}$ & $\begin{array}{l}\text { Students are able to experience, evaluate, } \\
\text { and use the knowledge and insights of local } \\
\text { experts in developing a research proposal. }\end{array}$ \\
\hline & & $\begin{array}{l}\text { Students experience communicating with } \\
\text { students from another cultural background, } \\
\text { and are able to reflect on the cultural } \\
\text { differences between Northern European } \\
\text { countries and the USA in the process. }\end{array}$ \\
\hline
\end{tabular}




\section{Courses}

At UG, Fieldwork Abroad is a mandatory course for all students. Scheduled at the end of their three year, English-language bachelor's degree program and complementing a final thesis, Fieldwork Abroad takes place on location in the last week of April and the first week of May, following preparation from December to March. In 2017-2018, 39 students participated; in 2018-2019, 28 students. Its main learning outcome is for students to apply the knowledge and communicative and research skills obtained in the undergraduate program in a (spatial) context that is unfamiliar to them. By using their knowledge of quantitative methods (surveying and regression analysis) and qualitative methods (interviewing and coding), students show they are able to devise and complete a largely independent group research project. This way, fieldwork is a type of experiential learning in which students learn about socio-spatial developments while on (international) location. The OIE project was added to the existing research project assignment in the course, and accounted for $2.5 \%$ of the overall course grade.

At DePaul, the OIE was part of the undergraduate program in Geography. In 2017-2018 it was embedded in the course GEO103 (Urbanization), in 2018-2019 in GEO299 (Knowledge, Place, and Power). Student numbers were 25 in 2017-2018 (GEO103) and 41 in 2018-2019 (GEO299). Both courses deal with the program learning outcomes that pertain to the construction of geographic knowledge, mainly in an urban setting, and interrogating geography's role in how space and place have been created to support and contest existing hierarchies. Topics covered in both courses include the spatial organization of housing and urban poverty, local governance, and issues of diversity, race, gender, and sexuality. As is typical of introductory courses offered in the American higher education system, these courses apply both to a bachelor's degree in Geography, and simultaneously fill 'general education' requirements. In this case, GEO103 contributes to a broad social science category, 'Social, Cultural and Behavioral Inquiry', and GEO299 contributes to 'Philosophical Inquiry'. Students from all disciplines are required to take one, two, or three courses in each general education category, depending on their primary program of study. Both GEO103 and GEO299 are taught from early January to mid-March. The OIE project was added to the existing assignments in the courses, and accounted for $15 \%$ of the overall course grade.

\section{Objectives}

A special feature of this OIE project is that the two courses did not have combined learning outcomes, activities, and assessments as would be expected from standard constructive alignment principles (Biggs \& Tang, 2011). Instead, a cross-course design was devised, based on the different roles the 
students had in the project. For the UG students, the explicit learning outcome of the OIE was to experience, evaluate, and use the knowledge and insights of local consultants in their research proposals. It was expected that the UG students could make more suitable and effective choices in their research projects based on accessing the local knowledge provided by DePaul students. A more tacit objective of the OIE was to experience communicating with students from another cultural background, learning to reflect on the cultural differences between The Netherlands and the USA in the process. Thus, the OIE outcomes contributed to the course outcomes by making students reflect on their knowledge, research, and communication skills in confrontation with the knowledge and research and communication skills of the DePaul students ('local consultants'). Moreover, by focusing the OIE outcomes on developing a research project and on active communication and reflection, the students would begin work toward attaining the experiential learning outcome in the preparation phase of the course.

For the DePaul students, the learning outcome was focused on intercultural awareness. The two DePaul courses contributed to the program's learning outcome that students will "interpret spatial patterns of economic inequalities and social injustices and their relation to urban, built, and natural environments”, (DePaul University, n.d.b, p. 458) and associated learning outcomes that advance student understanding of standard geographic concepts, in particular the city, society, place, region, and urban processes. By exchanging ideas, both groups of students were expected to start to reflect on their own and their fellow students' implicit ideas, and how these may differ between peers with different cultural and national backgrounds. The expectation was that an increased intercultural awareness through OIE would deepen the program learning outcomes: an increased knowledge of standard geographic concepts through reflecting on the role of cultural context in geographical knowledge, and increased reflection on the role of geography in creating, supporting, and contesting existing hierarchies, since these processes are placed and evaluated in a different cultural context.

\section{Project design}

The OIE consisted of UG students consulting with DePaul students during the preparatory phase of the UG students' research projects. During two videoconferencing sessions, DePaul students served as local consultants who gave advice, primarily about Chicago, to the UG students. DePaul students were not involved with conducting the research project during the fieldwork three months later, primarily because the academic calendar meant the DePaul course(s) had concluded prior to the UG students' arrival in Chicago. The UG research groups (consisting of four to five students) were paired with parallel groups of four to seven DePaul students by the DePaul teacher involved. Blackboard 
Collaborate Ultra was used as the technical tool for the videoconferencing, because it allowed videoconferencing to be recorded - a prerequisite for the Board of Examiners at UG.

The students were told the weeks in which to schedule two videoconferencing sessions, and were left to set their own meetings online. The first online meeting between the students was reserved for getting to know each other, building rapport, and having a discussion of the first research ideas of the UG students. In preparation for the second meeting, the UG students sent over their draft fieldwork proposals to the DePaul students. The DePaul students returned comments on these proposals and, during the second video meeting, discussed their feedback with the UG students. After these two videoconferences, the UG students finished and handed in their proposals to the UG supervisors.

In DePaul's courses, the students completed three separate assignments related to the OIE, each accounting for $5 \%$ of the student's overall course grade. The first assignment was to coordinate a video chat session, and then write a one to two page summary of the key parts of the conversation that made connections to and quoted course readings. In the second assignment, DePaul students provided feedback on the research proposals made by the UG students, relayed this feedback through videoconferencing and written comments, and followed up with a short reflection on the chat, again making connections to GEO103/GEO299 course content. These essays were graded on a scale of 0-100, based on evidence of integrating the course readings.

The final assignment for both UG and DePaul students was a reflection report based on a template designed specifically toward the OIE experience (see Appendix 1), that asked students to review and discuss the similarities and differences that they perceived between themselves and the students abroad, in terms of understandings of urban processes and other cultural observations. These reflection reports comprised $2.5 \%$ of the final course grade for the UG students, and $5 \%$ for DePaul students. The UG teachers graded the UG reflections on a scale of one to ten, according to the rubric provided in Appendix 2. The DePaul teacher graded the DePaul reflections on a scale of 0-100, without a rubric.

\section{Evaluation}

Both OIE specific and course module evaluations were conducted at UG and DePaul. For both student groups, a specific OIE evaluation was carried out in 2018 as part of the UG ENVOIE project in the form of an online survey. Unfortunately, only eight UG students and two DePaul students responded, a 15.6\% response rate. Likert scale questions were asked on four topics: intercultural 
learning outcomes, course integration and organization, technology, and overall appreciation. The response was positive, and the majority of the ten students favored using OIE again in future courses. In terms of learning, a majority of students indicated they had gained some intercultural learning experiences, valued the learning environment, and the autonomous working experience. However, the majority indicated that the OIE did not change their perception of the other country. This is not surprising given the setup of the OIE assignment, with just two relatively short videoconferences and few specific activities related to intercultural experiences.

Both the UG students and DePaul students also filled out their standard course evaluations, which took place after the end of term. The UG course ranked as the top student-rated bachelor course for the term both years. In both the UG and DePaul general course evaluation, no separate questions on the OIE component were included, and no remarks were made by students in the open fields of the questionnaires, except for one DePaul student who "loved the GLE stuff”!

\section{Data analysis}

Where the specific OIE evaluation yielded little response and the standard course evaluations did not specifically report on OIE, an initial thematic analysis (Braun \& Clarke, 2012) of the graded reflection reports gives an impression of how the OIE learning outcomes were experienced by the students.

\subsection{Disciplinary skills}

Students indicated that during the videoconferences they focused on the definition and (in)appropriate use of concepts such as race, spatial segregation, communities and neighborhoods, and the role of government. It was clear from the reflection reports that students on both sides came to realize through the OIE that the same disciplinary concepts could have different meanings: poverty for Dutch students may mean having to use a pre-paid cell phone, but for American students it may mean not being able to buy basic food supplies. Several UG students indicated that they had collected much information on Chicago in their preparation for the videoconferencing, but that their discussion with American students who had local knowledge and local awareness, changed their perspectives. Many UG groups reported that they rephrased research and survey questions, in particular regarding sensitive topics such as race, religion, income, and lifestyle. Overall, the reflection reports show that both the UG and DePaul students were positive about the OIE specifically for this reason: the UG students valued the advice from their counterparts on their research project, while the DePaul students valued their own roles as local consultants. 


\subsection{Intercultural awareness}

Both language and stereotypes can play a role in intercultural awareness (Buchtel, 2014; Kemmelmeier \& Kusano, 2018). In their assignments, American students often reflected on the Dutch students having a prejudiced view on American society. Both UG and DePaul students noticed that the others often started a discussion based on stereotypes, but learned about each other's more complex lived experiences during their conversations, which were positively appraised. An example in this regard is the notion of geographical scale. Several UG students indicated that although they knew the USA is huge in comparison to The Netherlands, the conversations made it clear to them what this means in practice for what they regarded as the local scale of Chicago. Dutch students learned how big Chicago is when being told by DePaul students of the likely travel times necessary to get to potential research areas. Interestingly, the UG students did not relate this understanding of Chicago's scale to the practical problems occasionally encountered when DePaul students were not in time for videoconferencing appointments or mentioned they needed reconfirmation of the appointment time before embarking on a (long) journey to DePaul's campus.

Further comparing the reflection reports of American and Dutch students, moments appeared in which stereotypes and preconceived ideas about the counterparts played a detrimental role to mutual understanding and intercultural awareness. Dutch students, for example, sometimes remarked that their American peers did not seem to talk as freely about issues of spatial and racial segregation as they did. Whereas the UG students explained this difference assuming that the DePaul students had a lack of knowledge about specific problematic neighborhoods in Chicago, or assumed that the stereotype of American political correctness must have been in play, some DePaul students indicated that they had learned in class that these issues are considerably more complex than outsiders often think. To the DePaul students, the UG students' direct way of approaching such research questions suggested naivety and a lack of awareness of this complexity. Echoing many of the DePaul student's sentiments in 2019, one wrote of a UG group examining food access: “they don't seem to find any issue with showing up in underserved areas and asking people about their eating habits”!

Schreiber (in press) suggests that in OIE projects, sometimes feelings of superiority interfere with the learning process. In the reflection reports of both DePaul and UG students, such feelings were sometimes expressed. As an extreme example, one UG student remarked that their counterparts were on a "clearly lower level of conceptual thinking". However, these examples were counterbalanced by frequent expressions of admiration for the others' levels of knowledge and insights throughout the reflection reports, in particular with regard to the command of English. Overall, many students indicated that learning first-hand about student-life in another country was enriching and increased their intercultural awareness, for example, noticing that the shared experience of being a student 
ameliorated cultural differences noticed between the Netherlands and the USA. DePaul students also reflected that these conversations led them to rethink their own roles in Chicago's urban geography, one remarking that "when asked about my own experience... I realized that I only go to those neighbourhoods to participate in gentrification".

\subsection{Grade development}

Student grades potentially reflect the effectiveness of the learning outcomes of the OIE experience. For the UG course, the expectation of implementing OIE was that it would positively influence the quality of the research projects. Figure 1 shows the UG grade variation for both the research proposal and the final research reports. The scores for years without OIE are drawn in gray, those for the years with OIE (2017-2018 and 2018-2019) are to the right, in black. For each year, the standard box plots show the lowest grade, the first quartile, the median, the third quartile, and the highest grade; the average grade is indicated by a cross.

Figure 1. EU grade variation development 2014-2019 (graded research proposal and research report)

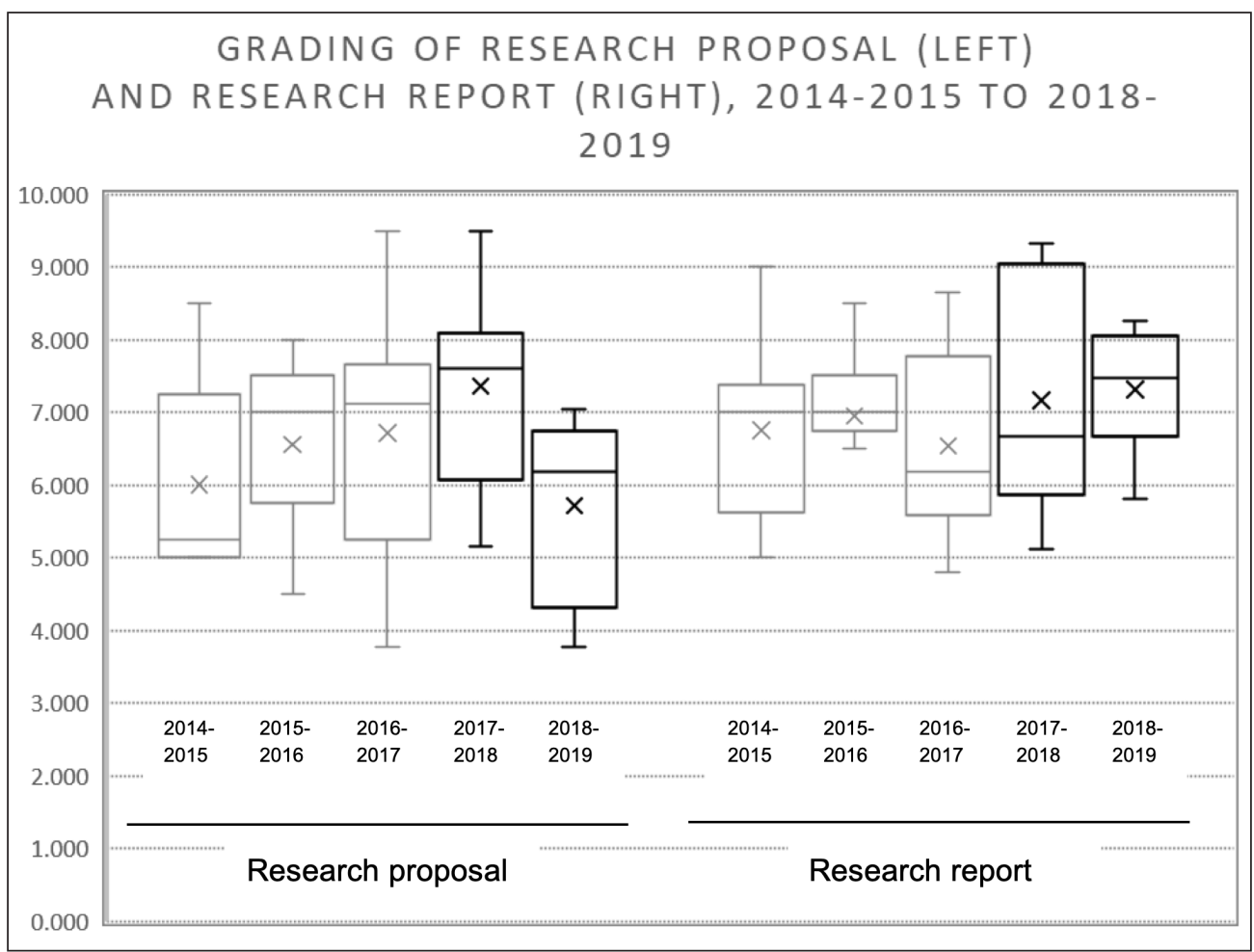


With one exception, the results do not show a decrease in grades for the years with OIE. On the other hand, a clear improvement is not visible either. With OIE, the average grade for the proposal rose from 6.4 to 6.7. For the research report it rose from 6.7 to 7.2. The one exception is the grading of the research proposal in 2018-2019. The average grade for this year, one with OIE, was historically low (5.7) and only just above the pass grade of 5.5. This seems to suggest that the OIE had not worked as expected, i.e. improving the quality of the research proposal. This also should not be surprising, since the proposal is graded on theoretical considerations and argued choices for research methods, and therefore DePaul students' local knowledge would not affect the grading that much. In fact, the deeper understanding of the local socio-spatial context that DePaul students provided, could have influenced the practical execution of the project and the interpretation of its results by UG students, leading to higher scores for the final research report as visible in the years with OIE. However, a multitude of factors can play into these relatively slight grade differences, so definitive conclusions about the effectiveness of the OIE cannot be drawn based on the grade development alone.

Given the different curricular contexts of the DePaul courses that were involved in these collaborations, a similar assessment of student grades was not applicable. Rather, the positive narrative comments made by students, as noted above, led to faculty deciding to continue these cross-course exchanges. Again, given the specific curricular context, a cross-course design makes most sense as DePaul has decided to partner the UG course with a different, upper-level, GEO333 Urban Planning course, which has few 'general education' students and more advanced Geography undergraduate (and some graduate) students.

\section{Lessons learned and questions for future implementation}

This practice report describes an OIE project that worked well because its cross-course design enabled relatively independent implementation in both existing courses, with different learning outcomes, requirements, and responsibilities for students on both sides, which allowed a level of flexibility in the organization of the OIE. For the UG fieldwork course, the OIE was meant to support the development of the research proposal, training students' disciplinary skills while developing intercultural awareness. Moreover, the assignment mimicked a situation that students potentially encounter in future professional practice, where plans and projects need to be developed with different stakeholders who may have diverging aims and purposes. For DePaul students, their role of local consultants created a reflection on the character of the city they live in, in line with the various affordances of virtual exchanges: "[seeing] themselves through the eyes of others" (Batardière et al., 2019, p. 2) and a confirmation of the value of their local knowledge. 
Thus, this cross-course OIE design aligned with the experiential learning philosophy central to the UG fieldwork course, and the intercultural awareness that was central to the DePaul internationalization project. Moreover, the cross-course design meant that the learning outcomes of the separate courses crossed over: both groups of undergraduates gained intercultural awareness and international perspectives, and for the UG students, OIE extended the experiential learning opportunities to the pre-mobility phase of their fieldwork course.

On top of that, a new, unexpected learning outcome surfaced through this specific OIE design. What we initially perceived as logistical challenges, namely that, (1) the courses did not run at the same time, either in terms of the academic year or weekday; and (2) due to the seven hour time difference between Chicago and Groningen, students from DePaul and UG had to work outside scheduled classroom periods, in practice translated into an appeal to the students' autonomy and taking ownership of the OIE. The students were free to negotiate the best place and time for the videoconferences, within the timeframe available for the assignments that was set by the teachers.

During the OIE, students showed different levels of interest in the assignments, resulting in different levels of responsibility and commitment: some student groups ran into trouble organizing the videoconferencing, and sometimes students remarked in their reflection reports on the disinterested attitude of their counterparts. Some DePaul students were enthusiastic about the video chats, others stated that these were an imposition on an already busy schedule. However, this aspect could contribute to a valuable learning experience for the students on both sides, preparing them for comparable practical problems they might encounter in their professional careers. By stimulating the cross-cultural project management skills of the students in this way, the OIE can potentially contribute to developing 'global citizens' (De Wit, 2016).

Two videoconferences are, of course, not enough to pick up a nuanced cultural sensitivity, which the reflection reports showed. As course designers we arguably underestimated the impact of prejudice and stereotypes about the USA and its residents with the UG students. Feelings of superiority that are often seen in OIEs (Buchtel, 2014; Kemmelmeier \& Kusano, 2018) were identifiable among some UG students, a number indicating in their reflection reports that the OIE did not change their impression of the USA. Implementing a discussion on stereotypes before the OIE assignment, and rephrasing the reflection report questions, could have prevented some of these presumptions. Indeed, in an informal manner, UG faculty and students more fully discussed stereotypes when on location during the Chicago fieldwork, and the UG students gradually seemed to become more open toward, and positive about, American culture and society. The DePaul students, on the other hand, seemed to have been generally more open and interested in Dutch culture and society 
during the OIE-phase already. Long-lasting contacts between the UG and DePaul students neither developed as a result of the videoconferencing, nor after providing the opportunity for the groups to meet during the UG students' visit to DePaul.

To conclude, for the supervisors this cross-course OIE design made the workload manageable, and added disciplinary knowledge and intercultural awareness to the courses in an interactive and student-led manner, encouraging a learning attitude that was central to both courses and to their respective internationalization programs. All in all, the OIE was positively assessed by both students and teachers and therefore has been continued. In a broader perspective, this innovative crosscourse design shows how OIE can be implemented flexibly within existing courses, supporting disciplinary specific skills and intercultural awareness. This potentially expands the application and benefits of OIE for the internationalization of higher education.

\section{References}

Batardière, M.-T., Giralt, M., Jeanneau, C., Le-Baron-Earle, F., \& O’Regan, V. (2019). Promoting intercultural awareness among European university students via pre-mobility virtual exchanges. Journal of Virtual Exchange, 2(1), 1-6.

Biggs, J. B., \& Tang, C. (2011). Teaching for quality learning at university (4th ed.). McGraw Hill Education.

Braun, V., \& Clarke, V. (2012). Thematic analysis. In H. M Cooper (Ed.), APA handbook of research methods in psychology (vol. 2, pp. 57-71). American Psychological Association.

Buchtel, E. (2014). Cultural sensitivity or cultural stereotyping? Positive and negative effects of a cultural psychology class. International Journal of Intercultural Relations, 39(1), 40-52.

DePaul University. (n.d.a). Global learning experience. https:/resources.depaul.edu/teaching-commons/programs/ global-learning/Pages/default.aspx

DePaul University. (n.d.b). DePaul University catalog 2019-2020. https://catalog.depaul.edu/university-catalogarchive/2019-2020/pdf/2019-2020_autumn.pdf

De Wit, H. (2016). Internationalisation and the role of online intercultural exchange. In R. O’Dowd \& T. Lewis (Eds), Online intercultural exchange: policy, pedagogy, practice (pp. 69-82). Routledge.

Hague, E., \& Groote, P. (2016). Van Burgess' grand opera tot strijd tegen gentrificatie. Geografie, 25(6), 6-9.

Kemmelmeier, M., \& Kusano, K. (2018). Intercultural competence: teaching it is worthwhile. In C. Frisby \& W. O’Donohue (Eds), Cultural competence in applied psychology. Springer.

Schreiber, B. R. (in press). "More Like You”: Disrupting native speakerism through a multimodal online intercultural exchange. TESOL Quarterly.

University of Groningen. (n.d.). ENVOIE. Enabling virtual online international exchange. https://www.rug.nl/let/onzefaculteit/organisatie/diensten-en-voorzieningen/ictol/projecten/envoie/ 


\section{Appendices}

\section{Appendix 1. Template for the students' reflection reports}

\begin{tabular}{|c|c|c|}
\hline $\begin{array}{l}\text { YOUR NAME, GROUP NUMBER } \\
\text { AND TOPIC }\end{array}$ & & \\
\hline & \multicolumn{2}{|c|}{ YOUR EXPERIENCE } \\
\hline & DIFFERENCES & SIMILARITIES/CORRESPONDENCES \\
\hline \multicolumn{3}{|l|}{ KNOWLEDGE } \\
\hline \multicolumn{3}{|l|}{$\begin{array}{l}\text { Terms used with a (somewhat) } \\
\text { different meaning by Dutch } \\
\text { respectively American students } \\
\text { (give examples and explain } \\
\text { briefly what the } \\
\text { differences/similarities are; } \\
\text { examples: city, neighbourhood, } \\
\text { community, environment, } \\
\text { government, politics, race, } \\
\text { poverty, ...) }\end{array}$} \\
\hline \multicolumn{3}{|l|}{$\begin{array}{l}\text { Tacit knowledge about e.g. the } \\
\text { city, neighbourhoods, } \\
\text { government, poverty, racial } \\
\text { and ethnic identities, } \\
\text { gentrification, etc.? }\end{array}$} \\
\hline \multicolumn{3}{|l|}{ SKILLS } \\
\hline \multicolumn{3}{|l|}{$\begin{array}{l}\text { Verbal communication: oral } \\
\text { and listening skills, ... }\end{array}$} \\
\hline $\begin{array}{l}\text { Non-verbal communication: } \\
\text { body language, ... }\end{array}$ & & \\
\hline
\end{tabular}




\begin{tabular}{|l|l|}
\hline \multicolumn{2}{|c|}{ YOUR SELF-REFLECTION } \\
\hline $\begin{array}{l}\text { Do you have a different } \\
\text { culture after this experience? } \\
\text { Please provide examples. }\end{array}$ & \\
\hline $\begin{array}{l}\text { Do you have a different } \\
\text { perspective on your own } \\
\text { (Dutch?) culture after this } \\
\text { experience? Please provide } \\
\text { examples. }\end{array}$ & \\
\hline $\begin{array}{l}\text { Do you have a different } \\
\text { perspective on yourself after } \\
\text { this experience? Please provide } \\
\text { examples. }\end{array}$ & \\
\end{tabular}

\section{Appendix 2. Grading rubric OIE reflection reports UG}

This is a digital grading rubric that automatically calculates the grade based on the boxes ticked by the grader. Feedback can be given in-text and through a feedback window in the software.

\begin{tabular}{|c|c|c|c|c|}
\hline \multirow[t]{2}{*}{ Criteria } & \multirow[t]{2}{*}{ Weight of criterium } & \multicolumn{3}{|c|}{ Levels of achievement } \\
\hline & & Novice (10\%) & Competent (70\%) & Proficient (100\%) \\
\hline $\begin{array}{l}\text { Reflection on differences/ } \\
\text { similarities knowledge/skills }\end{array}$ & $40 \%$ & & & \\
\hline $\begin{array}{l}\text { Depth of reflection } \\
\text { American and EU culture }\end{array}$ & $20 \%$ & & & \\
\hline Depth of self-reflection & $30 \%$ & & & \\
\hline Formalities (in time, spelling, etc) & $10 \%$ & & & \\
\hline
\end{tabular}




\section{Virtual Exchange?}

Published by University of Groningen Press | UGP, a not-for-profit press

Groningen, The Netherlands | UGP@rug.nl

(C) 2020 UNICollaboration (collective work)

(C) 2020 by Authors (individual work)

Journal of Virtual Exchange 2020

Edited by Carolin Fuchs and Müge Satar

Publication date: 2020/11/17

Journal of Virtual Exchange (JVE) is an online, open-access, peer-reviewed journal aimed at practitioners and researchers in the field known variously as virtual exchange, telecollaboration, or online intercultural exchange. It is the official journal of UNICollaboration (https://www.UNICollaboration.org/), the international academic organisation dedicated to supporting and promoting telecollaboration and virtual exchange in higher-level education.

Rights. The whole volume is published under the Attribution-NonCommercial-NoDerivatives 4.0 International licence (CC BY-NCND 4.0); individual articles may have a different licence. Under the CC BY-NC-ND licence, the volume is freely available online for anybody to read, download, copy, and redistribute provided that the author(s), editorial team, and publisher are properly cited. Commercial use and derivative works are, however, not permitted.

Disclaimer. University of Groningen Press does not take any responsibility for the content of the pages written by the authors of this article. The authors have recognised that the work described was not published before, or that it was not under consideration for publication elsewhere. While the information in this article is believed to be true and accurate on the date of its going to press, neither UniCollaboration nor University of Groningen Press can accept any legal responsibility for any errors or omissions. Additionally, the publisher makes no warranty, expressed or implied, with respect to the material contained herein. While University of Groningen Press is committed to publishing works of integrity, the words are the authors' alone.

Trademark notice. Product or corporate names may be trademarks or registered trademarks, and are used only for identification and explanation without intent to infringe.

Copyrighted material. Every effort has been made by the editorial team to trace copyright holders and to obtain their permission for the use of copyrighted material in this article. In the event of errors or omissions, please notify the publisher of any corrections that will need to by incorporated in future editions of this article.

Typeset by Research-publishing.net (https://research-publishing.net)

Noto fonts are open source. All Noto fonts are published under the SIL Open Font License, Version 1.1. Noto is a trademark of Google Inc. (https://www.google.com/get/noto/).

ISSN: 2647-4832 (online only)

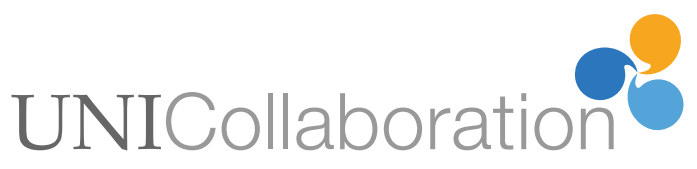

